\title{
Using Computer-Assisted Instruction and Developmental Theory to Improve Argumentative Writing
}

\author{
RONALD R. IRWIN Brock University
}

Keywords: dialectics, relativism, computer-assisted instruction (CAI), intellectual development, invention, heuristics, argumentative writing.

Abstract: A study is described in which the effectiveness of a computer program (Hermes) on improving argumentative writing is tested. One group of students was randomly assigned to a control group and the other was assigned to the experimental group where they are asked to use the Hermes program. All students were asked to write essays on controversial topics to an opposed audience. Their essays were content-analysed for dialectical traits. Based on this analysis, it was concluded that the experimental group wrote more dialectically effective essays than the control group, and the amount of difference between the control and experimental groups was related to the students' intellectual developmental level, as assessed by the Measure of Epistemological Reflection (MER). It is concluded that argumentative writing, operationalized here as dialectical writing, can be improved by computer-assisted instruction, but that attempts to teach such forms of thinking and writing need to take into account students ${ }^{y}$ capacity to benefit from such instruction. Such capacity is defined here as intellectual development.

\section{Introduction}

I developed a computer program that would provide instruction to university-level students in how to write essays exhibiting qualities of mature writing and thinking: such characteristics had been described in a number of contexts by developmental psychologists as relativistic (Perry, 1970), dialectical (Basseches, 1986) or metasystematic (Commons, Richards \& Armon, 1984). ${ }^{1}$ Many of these characteristics seemed at the time to overlap with characteristics that teachers of composition emphasized as well (Elbow, 1986; Young, Becker, \& Pike, 1970). At that time as a writing instructor I was frequently confronted with writing that evidently lacked many of these qualities. I was interested in whether such a program could "artificially" teach students how to think in a more mature fashion and whether it could improve their writing. I was also considering the hypothesis that because of developmental limits no improvement could be made by means of instruction. The following outlines the steps carried out in studying these questions and the relative success of such a program in teaching better thinking and writing.

Many methods have been proposed to teach critical thinking or informal reasoning. One important method is writing instruction (Perkins, 1985); composition and rhetoric theorists seem to agree that informal logic and critical thinking are a part of their domain (Young, Becker, \& Pike, 1970). But more important, the act of writing is thought to be intrinsically dialectical, and therefore conducive to thinking critically (Elbow, 1986; Harris, 1986; Hays, 1983). One reason for this is that the teaching of writing is a specific training in discourse; discourse is social and involves perspective-taking and considerations 
of audience, hence it is dialectical. Another reason is that writing, because it externalizes the products of thinking, makes it easier to operate upon the products of thinking; that is, upon ideas. Because dialectic is a form of thinking about thinking, or thinking about ideas, writing makes it more likely that such thinking will occur.

Writing objectivizes thought in ways that conversation does not. In conversation, one can externalize thinking to some extent, and thus hold it up to view for criticism; but the situation fluctuates too much to allow for sustained critical examination. By contrast, writing objectifies and spatializes thought (Ong, 1982); it preserves it and makes it an object to reflect upon.

The ability to separate one's thoughts from immediate reality and to operate upon the products of language itself is said to take place only through writing - in part because short-term memory restricts what can be held in immediate consciousness, but also in part because it is the structure and linearity of written language that impose form and order (Hays, 1983, p. xi).

Peter Elbow (1986) portrays writing as a vehicle of self-reflection comparable to other artistic forms:

Language is the principle medium that allows you to interact with yrself. (Painters do it with shapes and colours, composers with music and sounds.) Without a symbol system such as language, it is difficult if not impossible to think about more than one thing at a time, and thus to allow two thoughts to interact and cook. Putting a thought into symbols means setting it down and letting the mind take a rest from it. With language you can put an idea or feeling or perception into words - put it in yr cud or in your freezer and then go on and have a different one and not lose the first. In this way, you can entertain two thoughts or feelings at the same time or think about the relationship between two thoughts or feelings. A principle value of language therefore, is that it permits you to distance yrself from your own perceptions, feelings, and thoughts. (p. 45.)

Writing, as a symbolic system, provides a cultural tool or prosthesis for holding the products of thinking before us so that the limits of such thinking can be more easily transcended once they become the objects of reflection. Limitations in thinking occur for a number of reasons. Perhaps the chief such cause of limitation is the shortness of the span of attention. Writing is a method of artificially adding to what can be processed in the span of attention so that symbolic objects can stand for ideas that would not otherwise be held in what psychologists call working memory.

Writing would seem then to provide the ideal method for teaching students how to reason more reflectively, but learning to write is difficult for the beginner. Indeed, for many students, the act of writing seems to hamper thinking. One reason for this is that for most people writing is unusual in the extent of its solitary nature. Many aspects of the discourse situation are inherently social, but in the act of writing these must be cognitively represented and imagined ('modeled'). For example, the problem requiring a practical solution, the audience 
to be addressed and how it perceives the situation, one's goals and purposes in writing, must all be cognitively imagined since they are not physically present. When one adds to that the demand on thinking to coordinate such mechanical elements as grammar, punctuation, spelling, and formatting (many of which are unfamiliar to students), it is no wonder that students often fail to write effective essays.

In the following it will be argued, and evidence will be adduced, that argumentative writing may require a level of cognitive development beyond that of most undergraduates. Preliminary support for this contention can be found in Hays, Brandt, and Chantry (1988) and Hays, Durham, Brandt, and Raitz (1990) who showed that intellectual development clearly predicted quality of argumentative writing. Although our intention may be to teach writing skills to expand our students' critical thinking abilities, good writing assumes the very abilities we are trying to instruct. We may teach writing with the purpose of developing dialectical or rhetorical abilities in our students-such as an awareness of different audiences, how to objectivize the products of thinking, how to reason from different points of view, how to argue and persuade effectively-however, these same abilities may be necessary to acquire many writing skills. Without such abilities students are unable to assimilate the instruction and in practice will fail to coordinate the various skills necessary to perform effectively.

Composition and rhetoric theorists and teachers have used a number of techniques to address various aspects of the writing process: rhetorical invention, peer review and tutoring, modelling of effective writing and argument, the teaching of revision skills, and more recently, collaborative writing by means of computer networking and electronic mail. But does the teaching of a variety of writing skills that for students may not be related leave unaddressed the issue of bringing the various skills together?

It will be proposed here that the capacity to engage a reader dialectically is due to the existence of specific mental structures that plan, anticipate and monitor mental representations and which allocate mental resources such as attention and interruption (such structures are elsewhere referred to as executives, see PascualLeone, 1983, 1984, 1990a, 1990b). These structures can control and monitor the employment of writing skills. These same structures manifest themselves as part of mature intellectual development and are explained by some neo-Piagetian psychologists as being due to further logical-structural development beyond formal operations (Inhelder \& Piaget, 1958). Such development is said to be measured by the Measure of Epistemological Reflection (MER). Writing skills may be taught, modelled, or scaffolded, but unless they can be coordinated by these developmental structures, the skills taught will not be generalized or applied beyond the local context of instruction.

One method of developing student's writing skills is to teach rhetorical heuristics, a method going back at least to the time of Aristotle. Several such methods have been programmed for use on a computer (Burns, 1983; 1984; 
Burns \& Culp, 1980; Kemp, 1987a; 1987b) and a number have been included in programs such as Daedalus that cover many of the various phases of the writing process, including collaboration and networking (LeBlanc, 1993; Schwartz, 1984; Wresch, 1984).

Many different programs have been designed for the invention or pre-writing phase of composition, the earliest going back to Burn's original study (1983), which was subsequently included in Daedalus. The heuristics program described in this section differs from others because it is designed for a later phase in the writing process than are the invention programs, that is, for the stage in the student's writing after a provisional thesis is constructed but before the student has begun to arrange their ideas into a coherent text.

Heuristics are "explicit strategies for effective guessing." They provide "a series of questions or operations whose results are provisional. Although explicit and more or less systematic, heuristic search is not wholly conscious or mechanical; intuition, relevant knowledge, and skill are also necessary." (Young, 1980 , p. 345).

Hermes is a computer program designed with a structured method of heuristic thinking incorporating aspects of cognitive-developmental theory (Basseches, 1984; Perry, 1970) with what is normally taught as rhetoric and composition theory (Young, Becker, \& Pike, 1970). The intention is to have a student think dialectically about their thesis and consider rhetorically how their position will be received by an audience. Both processes are considered to require making an interpretation of the thesis to the reader. As heuristics, the program is an open-response sequencing of questions and prompts intended to stimulate a critical reflection on the thesis to be argued.

There are two parts to Hermes: the first part elicits a thesis and then asks the student to reflect upon it and the frame of reference or perspective it entails. Concrete examples are illustrated to prompt the student to critically reflect on their own point of view so that they can become aware of it and how it shapes the development of their thesis and argument. They are then asked to consider an alternative point of view and to imagine what thesis they might hold given that other point of view. Next they are asked to carry out an attempt to dialectically coordinate the different points of view by comparing similarities and differences between them, and thus to evolve a more integrated perspective.

The second part of the program asks the student to try to reflect upon their thesis as it might be perceived by their audience. Most of the specific thetorical content of this part is derived from Young, Becker, and Pike (1970), who synthesized elements of traditional rhetoric with modern writing process theory and Rogerian argument (a form of persuasion anchored in client-centred therapy). The aim of this part is to get the student to consider how their ideas will be received by their reader. The focus is on making the writer aware of how the reader's image of the issue is different from the writer's image and what may be done to bridge these differences in perception and outlook. 
Hermes is written in Emacs Lisp to be run on a networked Unix system. Emacs is a programmable display editor that can be altered in its functioning and appearance with windows, menus and embedded text, accept input and retrieve files, as well as enable a user to do word-processing. ${ }^{2}$ It is ideal as a program which can be made to combine embedded instruction with text-editing. In Hermes, students generally read various windows in the upper part of the screen and enter responses in the lower window. They are presented with opportunities to repeat sections of the program if they need clarification and often work from menus in order to focus on concerns they choose to work on. Hermes can retrieve text the student has typed in earlier and redisplay it on the terminal along with preprogrammed text, thus appearing to question the student about their specific answers regarding thesis, assumptions, point of view, intended audience, and so forth.

After it is used, a transcript is stored of the questions and answers in the session. The Unix system was programmed to send the transcript file to the experimenter's directory after the session was finished, where the student's answers were content analysed.

The basic questions addressed were: (1) whether programmed instructional heuristics can improve argumentative writing, (2) whether a measure of developmental level can predict argumentative writing above and beyond what a knowledge of age and grade level alone or together can predict, and (3) whether the effects of programmed heuristics are mediated by developmental level.

\section{Method}

Developmental level is operationalized by the Measure of Epistemological Reflection (MER), a measure of Perry position level. William Perry's (1970) theory of late adolescent development is one proposed model of what is sometimes referred to as post-formal operational development. The MER was designed and validated by Baxter-Magolda and Porterfield (1988), based upon the methodology established for Gibbs and Widaman's (1982) Sociomoral Reflection Measure (SRM), which was developed to assess Kohlberg's stage theory of moral development. The MER assesses only Perry positions one to five, its developers arguing that the latter Perry positions (six to nine) do not address genuine structural change and lack demonstrated empirical validity.

An experimental design was used with subjects randomly assigned to the control or experimental groups. The experimental subjects used Hermes and the regular instructions; the controls received only the regular instructions. The dependent variables for all subjects were based on the Primary Trait Scores (PTS) of their essays. The independent variables were: age, educational level, sex, motivation (as assessed by a number of measures and scales), intellectual development (using the MER) and a number of demographic measures, as well as the manipulation of the treatment. Only the independent variables pertaining to development will be discussed here. 
The subjects were 24 volunteers solicited at York University's Computer-Assisted Writing Centre during the 1991/92 academic year. They were reimbursed for taking part in the experiment and were told they would be involved in testing new instructional software. They were all regular users of the centre, willing to learn about new writing programs. Their work was not a part of any course.

Each student began by using a Unix shell program, which provided all of the regular instructions, at the beginning assigning them randomly to either the control or experimental groups. Students then chose the assignment they were going to work on, were given a rhetorical or argumentative task, and were then asked to complete the work in two weeks. They were instructed to contact the experimenter by phone or electronic mail when they had finished.

All of the regular instructions and housekeeping tasks were taken care of by the Unix program: assignment to groups, storage of files, saving of previous choices, and structuring and guiding the method of composition by a menu that incorporated Linda Flower's (1989) nine steps in the composing process. The latter is based upon teaching the student to break down a writing task into steps which can be worked on one at a time. Each of the steps involves such things as instructions to brainstorm, to organize by outlines, revise for a reader, and so forth.

When the Unix program was first used, students were assigned a condition and selected the essay topic and position to argue for or against. Each subsequent time the students worked on the essay, the writing assignment, the instructional material, as well as the menu for Flower's steps in the composing process, were all re-displayed. The students chose which of Flower's steps they wanted to work on and then the program explained that step in the writing process. The students indicated when they were ready to continue and the Unix program placed the students in the text-editor. While working within the text-editor, the students were able to re-display the rhetorical assignment by pressing a specific key.

There were four topics. The students were asked to select one in the first session based on their interest and willingness to write on it. These were: abortion, censorship of pornography, the value of a liberal arts education, and capital punishment. Students were asked what position they wished to argueeither for or against-and their choices determined the rhetorical assignment they worked on.

The students were asked by means of the program to address their argument to another student who held a different viewpoint to their own on the same topic. They were also informed that their paper was to be used in a latter phase of the project and read by students who took an opposite point of view to their own on the same issue. Later they would receive feedback from them electronically.

The experimental group was asked to use the heuristics program 'Hermes' midway through their writing assignment. The controls simply continued with their writing assignment. Aside from whether they were asked to use the Hermes 
program or not, there were no systematic differences between the two groups (group selection having been determined by random assignment).

The experimental students were instructed to start the Hermes program when they felt they had developed the essay to the point where they had a working thesis. They were asked to use Hermes in one session only, and afterwards the stored file of the interaction was mailed to a directory. Students were given the option of having the file mailed to them if they wanted to review the session.

\section{Results and Discussion}

The six sections of the Measure of Epistemological Reflection (MER) were analysed separately. ${ }^{3}$ These sections were: Decision Making in an Educational Context, the Role of the Learner in the Learning Process, the Role of the Instructor in the Learning Process, the Role of Peers in the Learning Process, the Role of Evaluation in the Learning Process, and the Nature of Knowledge, Truth, and Reality. The mean score was 3 (the levels varied from 1 to 5 ) and the standard deviation was .58 .

These scores were compared statistically to the other variables in the study. Chiefly of interest were the findings that MER was correlated .69 to quality of written essay as assessed by PTS (see below), .43 to age, .46 to educational level and .55 to number of hours worked. Of somewhat less importance were the findings that MER was correlated .28 to level of reported stimulation, .24 to motivation, .22 to amount learned, and -.20 to extent to which they felt they had influenced their reader and -.24 to number of sessions worked. The MER seems to predict the quality of students' essay writing very well. It is also related to a number of effort and interest variables and significantly to how many hours a student worked. It is also somewhat negatively related to the extent to which a student felt they had influenced their reader; in other words, those at higher developmental levels seem less confident of how much their writing influences others.

The Primary Trait Scores (PTS) were computed in the following way. With the purpose of identifying qualities in the essays that reflected characteristics relevant to the intent of the instructional computer program, I analysed a sample of twenty essays. I first extracted a list of over 120 descriptors. With the intent of extracting a few fundamental dimensions, the list was placed in a Unix file and a Unix sort utility was applied to the coded items in the file. Items were first coded and then sorted on the basis of whether the item was relevant to the writer, the reader, the subject of the discourse, or to textual qualities. After the items were grouped on this basis the items were coded and sorted for possessing either positive or negative rhetorical qualities. After reading the grouped items a pool of nine dimensions was formed, deleting items considered redundant or of no interest to the hypotheses of the project. From these, the following six dimensions were selected and a rating manual was constructed. 
A) Role of Self: that is, the extent to which the writer acknowledges the role of their own personal subjectivity in forming their views and what they write.

B) Working with Reader's Views: that is, the willingness and capacity to intellectually address and work with their reader's views and arguments.

C) Sharing with Reader's Concerns, Values, and Feelings: that is, the writer's willingness and capacity to empathically work with their reader's feelings, values, needs, etc.

D) Role of Truth in Argument: or how sophisticated is the writer's way of making truth claims or assertions.

E) Use of Reader-Based Prose: the extent to which the writer structures and organizes their text for a reader to follow.

F) Framing of Issue: how aware the writer seems to be of the necessity of establishing a conceptual framework for their reader so that they may understand what is being discussed.

Using these six dimensions, each was subdivided into a continuum from 0 to 5. A 0 score indicated a total absence of the relevant quality and a score of 5 indicated high rhetorical or dialectical qualities. Five essays were scored using these six dimensions, and the gradations were adjusted so that a reader could both reliably discriminate along each of the continuums and so that real differences could be reliably identified for each of the points along the dimension. These Likert-type scale items were included in the rating manual. As scoring of the final essays progressed the descriptions for each of the gradations was refined although the numbered scale itself was not altered. For each item in the manual, a description of the dimension was provided, along with a question a rater should be asking him or herself when determining if the dimension was relevant to the text being analysed.

In order to insure reliability and accuracy, the manual included instructions to the rater to read the entire essay over initially, and then to read each paragraph separately while coding for the presence of each dimension. Thus, during coding each paragraph was analysed six times. The essay was coded with a macro each time the dimension was found in the text, along with a tentative rating for the passage in question. Afterwards, the lines in the file were numbered with an emacs function. The line number, tentative rating, and comments explaining the rating were then written down in the manual. After reading the ratings, a combined score for each dimension was determined for the essay as a whole, which was not an arithmatic averaging of the particular scores but a score for the essay as a whole. With the resulting coded essay and the annotated rating manual, a justification could be provided for ratings given.

Table 1 shows the distribution of scores for each of the traits measured, as well as the average of the traits for the essays. 
Note that both Role of Self and Role of Truth have the lowest mean scores. Regarding Role of Self, this may be interpreted to mean that students do not take ownership for their own writing as their writing. They tend not to use the personal pronoun and they tend to downplay their own active role in the development and construction of meaning. Of course, this can be seen not just as a function of their development, but also as a result of traditional academic pressures to write in an "objective" voice. Scores on this dimension are not related to age and only slightly related to educational level $(r=.18)$, but moderately related to MER score $(r=.34)$. The experimental group had higher scores on this dimension than the control $(1.79$ versus 1.05$)$ and this tested as significant as a whole. ${ }^{4}$

TABLE 1: Primary Trait Scores

\begin{tabular}{lrrrr}
\hline Trait & Mean & SD & Minimum & Maximum \\
Role of Self & 1.48 & 1.02 & 0.00 & 3.40 \\
Working with & 3.41 & 1.15 & 1.00 & 5.00 \\
$\quad$ Reader's & & & & \\
$\quad$ Views & 2.33 & 1.11 & 0.50 & 5.00 \\
$\begin{array}{l}\text { Sharing with } \\
\quad \text { Reader }\end{array}$ & 1.89 & 1.19 & 0.50 & 4.30 \\
$\quad$ Role of Truth & 2.81 & 1.12 & 0.50 & 4.60 \\
$\begin{array}{l}\text { Reader-Based } \\
\quad \text { Organization }\end{array}$ & 3.30 & 0.83 & 2.20 & 4.70 \\
$\quad$ Framing & 2.54 & 0.77 & 1.32 & 4.15 \\
\hline Average Score & & & &
\end{tabular}

Regarding Role of Truth, the scores overall were not as low as Role of Self. They were also more strongly related to the developmental variables being studied. Role of Truth correlated .31 with age, .46 with educational level and .56 with MER. The experimental group scored 2.4 and the control scored 1.2 and this difference tested significantly. Students seem to have a more dualistic manner of making truth claims in their writing than might have been predicted, and this tendency is related to their development, but this dimension can be influenced by instruction.

The other scores were higher. Working with Reader's Views was strongly related to the main developmental variables: $r$ of .24 with age, .59 with educational level and .69 with MER. However, the experimental group did not receive significantly higher scores on this dimension than the control group (3.66 versus 3.06). The ability to actively address reader's views, opinions and assumptions seems to be resistant to the type of instruction offered and somewhat anchored to the developmental level of the student.

Sharing with Reader's Views is less strongly related to the developmental variables studied than Working with Reader's Views. Sharing was correlated with 
age at .18 , to educational level at .52 , and .35 with MER. There was a difference between the experimental and control groups in the predicted direction (2.59 versus 1.97 ) but this difference only approached statistical significance. Reader-Based Organization was only moderately related to the developmental variables studied: it correlated .28 with age, .25 with educational level and .44 with MER. The experimental manipulation had no effect whatsoever on this dimension; in fact, the scores were in the opposite direction than hypothesized (2.73 versus 2.92 ), but this did not test as significant. The use of organizational strategies in writing is partially related to development but is not affected by the kind of instruction offered in this study.

Framing was more strongly related to the developmental variables studied: it correlated .47 with age, .49 with educational level, and .60 with MER. It was also affected by the instruction provided: the experimental group scored 3.55 while the control scored 2.96, and this difference tested significantly. Framing seems to be a relevant developmental dimension and is affected by instruction of the kind in this study.

The relationship between the Primary Trait Scores (PTS) and each of the developmental variables was examined next. The strongest relationship was between PTS and MER; the correlation was .69. Educational level and PTS correlated .58 while age and PTS correlated .34. Because these three independent variables were correlated, each of these relationships with PTS was further tested by a partial correlation procedure, each tested while controlling for the other two. The partial correlation of MER and PTS, controlling for educational level and age, was .58. The partial correlation of educational level and PTS, controlling for MER and age, was .41. The partial correlation of age and PTS, controlling for MER and educational level, was -.08 . So in fact, the relevant variables related to essay writing ability are developmental level and education, and not age per se.

The average PTS (over the six dimensions) of the experimental group was 2.78, while the PTS of the control was 2.19. This tested significant (although only with a one-tailed test). It can be concluded that students who used Hermes wrote better essays than those who did not. Because not all students seemed to have benefitted from the instruction offered in Hermes, the following comparisons were made.

Because educational level and MER were so strongly related to PTS the effects of the treatment were compared separately for levels of education and MER in Tables 2 and 3. 
TABLE 2: Treatment Effects by Educational Level (years of university education)

\begin{tabular}{lrrr}
\hline Level & & Treatment \\
& Hermes & & Control \\
1 & 2.48 & $<$ & 2.57 \\
2 & 1.75 & $<$ & 1.89 \\
3 & 2.43 & $>$ & 2.21 \\
4 & 3.58 & $>$ & 3.28 \\
$4+$ & 3.50 & & -
\end{tabular}

TABLE 3: Treatment Effects by Measure of Epistemological Reflection (MER)

Level

$<2.5$

GE 2.5 and $<3$

GE 3 and $<3.5$

GE 3.5
Treatment

Hermes

1.87

2.53

2.83

3.40

Control

1.97

2.24

2.06

2.57

We can see that small treatment effects occurred within educational levels three and four (and perhaps four plus had there been any subjects in both cells); by contrast, there were stronger effects within the third and fourth developmental levels of MER. There was no effect for educational levels one and two, no effect for epistemological level one, and only a very small effect for epistemological level two. The instruction provided by Hermes benefited only those of higher educational levels and higher epistemological levels. Although devised to assess relativistic reasoning, the MER also seems to predict the student's capacity to benefit from instruction in dialectical thinking (if that is indeed what we can assume that Hermes is). As was initially argued by Basseches (1984) in his account of Perry's (1970) description of relativism, relativistic reasoning may be an early form of dialectical reasoning. Dialectical reasoning may be distinguished from relativistic reasoning in the greater emphasis it places upon integrating contradictions.

In conclusion, the writing of argumentative essays by students is strongly related to Perry developmental level, as assessed by the MER. This provides evidence of the construct validity of the MER as a measure of developmental level and is in accord with the findings of Hays et al (1988; 1990). However, essay writing can be improved significantly by developmentally-oriented instruction, although such improvement seems anchored to developmental level.

Level of intellectual development is a significant predictor both of argumentative essay writing ability and capacity to benefit from a specifically dialectical method of instruction. And it is a better predictor of writing than simply knowing the student's age or educational level. 
These results suggest that we need to consider a student's intellectual development when teaching methods of critical thinking, and furthermore, that we need to understand the student's stage of intellectual development. While I have previously addressed problems with a "stage" theory of development (Irwin, 1991; Irwin \& Sheese, 1989), these results indicate the validity of a stage measure of relativistic thinking in providing a diagnosis of the Zone of Proximal Development $(Z P D)$ - the capacity to benefit from instruction-of dialectical thinking.

${ }^{1}$ The following is based upon the author's (Irwin, 1995) dissertation entitled "Intellectual development and computer-assisted instruction: the improvement of dialectical thinking and argumentative writing" completed at York University's Department of Psychology in 1995. Data was collected at York's Computer-Assisted Writing Centre. Gratitude is acknowledged to the staff and students of the Centre and to its Director, Mary-Louise Craven. Fuller details regarding the method and analysis can be found in the dissertation.

${ }^{2}$ I wrote the Hermes program in Lisp as part of the Emacs display editor which was run on Unix platform at the Computer-Assisted Writing Centre at York University in Toronto. Technical assistance was provided by Steve Azmier. I used Gnu Emacs version 18.55, written by Richard Stallman (1987) in C and Lisp.

${ }^{3}$ Copies of the MER questionnaire were sent to Molly Schaller, a certified rater trained with Marcia Baxter-Magolda, who had rated over a thousand protocols. The questionnaires sent to Shaller contained no subject information except identification number. After Schaller completed the scoring using the Baxter-Magolda and Porterfield (1988) method, a scoring sheet was returned to the author with the MER scores. Schaller kept the copies of the MER forms which she had scored. She reported that the scores of the subjects in this study were somewhat higher than normal for university students.

${ }^{4}$ While coding I was blind to any identifying subject information. As an inter-rater reliability check, four essays from the study were randomly sampled and sent, along with the scoring manual, to Dr. Ronald L. Sheese, an experienced writing instructor and Director of York University's Centre for Academic Writing. With a minimum of instruction the correlation between his rating and that of the author was over .88 for the average of the six dimensions. Dr. Sheese's participation is gratefully acknowledged.

\section{References}

Basseches, M. (1984). Dialectical thinking and adult development. New Jersey: Ablex.

Baxter Magolda, M. \& Porterfield, W. D. (1988). Assessing intellectual development: The link between theory and practice. Maryland: American College Personnel Association.

Burns, H. (1983). A writer's tool: Computing as a mode of inventing. In J. Hays, P. Roth, J. Ramsey, \& R. Foulke, (Eds.), The writer 's mind: Writing as a mode of thinking (pp. 87-94). Urbana, IL: National Council of Teachers of English.

Burns, H. (1984). Recollections of first-generation computer-assisted prewriting. In $W$. Wresch, (Ed.), The computer in composition instruction: A writer's tool (pp. 15-33). Urbana, IL: National Council of Teachers of English.

Burns, H. \& Culp, G. H. (1980). Stimulating invention in English composition through computer-assisted instruction. English Technology, August, 5-10.

Commons, M. L., Richards, R., \& Armon, C. (Eds.). (1984). Beyond formal operations: Late adolescent and adult cognitive development. New York, NY: Praeger. 
Elbow, P. (1986). Embracing contraries: Explorations in learning and teaching. New York, NY: Oxford University Press.

Flower, L. (1989). Problem-solving strategies for writing (3rd ed.). New York, NY: Harcourt, Brace, Jovanovich.

Gibbs, J. C., \& Widaman, K. (1982). Social intelligence: Measuring the development of sociomoral reflection. Englewood Cliffs, NJ: Prentice Hall.

Harris, M. (1986). Teaching one-on-one: The writing conference. Urbana, IL: National Council of Teachers of English.

Hays, J. N. (1983). The development of discursive maturity in college writers. In J. N. Hays, P. Roth, J. Ramsey, \& R. Foulke, (Eds.), The writer's mind: Writing as a mode of thinking. (pp. 127-144). Urbana, IL: National Council of Teachers of English.

Hays, J. N., Brandt, M. \& Chantry, K. H. (1988). The impact of friendly and hostile audiences on the argumentative writing of high school and college students. Research in the Teaching of English, 22: 391-416.

Hays, J. N., Durham, R.L., Brandt, K.S., \& Raitz, A.E. (1990). Argumentative writing of students: Adult socio-cognitive development. In G. Kirsh, \& D.H. Roen, (Eds.), A sense of audience in written communication (pp. 248-266). Newbury Park: Sage.

Inhelder, B. \& Piaget, J. (1958). The growth of logical thinking from childhood to adolescence. (A. Parson \& S. Milgram, Trans.). New York: Basic Books. (First published 1955.)

Irwin, R. R. (1991). Reconceptualizing the nature of dialectical postformal operational thinking: The effects of affectively mediated social experiences. In J.D. Sinnot \& J. C. Cavanaugh, (Eds.), Bridging paradigms: Positive development in adulthood and cognitive aging (pp. 43-57). New York, NY: Praeger.

Irwin, R. R. (1995). Intellectual development and computer-assisted instruction: The improvement of dialectical thinking and argumentative writing. Unpublished doctoral dissertation, York University, Toronto, Ontario, Canada.

Irwin, R. R., \& Sheese, R. L. (1989). Problems in the proposal for a "stage" of dialectical thinking. In M. L. Commons, J. D. Sinnott, F. A. Richards, \& C. Armon, (Eds.), Adult development, Vol. II: Comparisons and applications of developmental models (pp. 113-132). New York, NY: Praeger.

Kemp, (1987a). Getting smart with computers: Computer-aided heuristics for student writers. The Writing Centre Journal, 8, (1), 3-10.

Kemp, F. (1987b). The user-friendly fallcy. College Composition and Communication, 38: 32-39.

Leblanc, P. (1993). Writing teachers writing software. Urbana, IL: National Council of Teachers of English.

Ong, W. (1982). Orality and literacy: The technologizing of the word. New York, NY: Methuen.

Pascual-Leone, J. (1983). Growing into human maturity: Toward a metasubjective theory of adulthood stages. In P. B. Baltes \& O. G. Brim, (Eds.), Life-span development and behaviour. Vol. 5, (pp. 117-156). New York, NY: Academic Press.

Pascual-Leone. J. (1984). Attentional, dialectic, and mental effort: Toward an organismic theory of life stages. In M. L. Commons, F. A. Richards, \& C. Armon, (Eds.), Beyond formal operations: Late adolescent and adult cognitive development (pp. 182-215). New York, NY: Praeger. 
Pascual-Leone, J. (1990a). Reflections on life-span intelligence, consciousness, and ego development. In C. N. Alexander \& E. J. Langer, Higher stages of human development (pp. 258-285). New York, NY: Oxford University Press.

Pascual-Leone, J. (1990b). An essay on wisdom: Towards organismic processes that make it possible. In R. J. Sternberg, (Ed.), Wisdom: Its nature, origins and development (pp. 244-278). New York: Cambridge.

Perkins, D. (1985). Postprimary education has little impact on informal reasoning. Journal of Educational Psychology, 77 (5): 562-571.

Perry. W. G. (1970). Forms of intellectual and ethical development during the college years. New York, NY: Holt, Rinehart, \& Winston.

Schwartz, H. J. (1984). SEEN: A tutorial and user network for hypothesis testing. In W. Wresch, (Ed.), The computer in composition instruction: A writer's tool (pp. 47-62). Urbana, IL: National Council of Teachers of English.

Stallman, R. (1987). GNU Emacs Manual. (6th ed.). Cambridge, MA: Free Software Foundation.

Wresch, W. (Ed.), (1984). The computer in composition instruction: A writer's tool. Urbana, IL: National Council of Teachers of English.

Young, R. (1976). Invention: A topographical survey. In G. Tate, (Ed.), Teaching composition: Ten bibliographical essays. (pp. 1-43). Fort Worth, TX: Texan Christian University Press.

Young, R., Becker, A., \& Pike, K. (1970). Rhetoric: Discovery and change. New York, NY: Harcourt, Brace, \& World.

RONALD R. IRWIN DEPARTMENT OF CHILD STUDIES BROCK UNIVERSITY ST. CATHARINES, ON L2S $3 A I$ 